Revista de Derecho

\title{
La dama de la justicia y su representación en el séptimo arte
}

The representation of the Lady of justice on the seventh art

\author{
Andrés Rodrigo Ramírez Salazar \\ Defensoría Pública del Ecuador \\ andre1225@hotmail.es
}

DOI: https://doi.org/10.32719/26312484.2019.31.1

Fecha de recepción: 15 de marzo de 2018

Fecha de aprobación: 26 de febrero de 2019 


\section{RESUMEN}

El derecho y el arte tienen algo en común: su carácter humanístico. Por otro lado, la justicia, como ideal, ha sido representada desde las más variadas concepciones culturales y artísticas. La tradición occidental, por ejemplo, nos ofrece la imagen de una mujer que utiliza una venda en su rostro, armada en una mano con la balanza de platillos y en la otra con una espada, prestándonos elementos que permiten jugar con esa iconografía. Entonces le dotamos de significado: suponemos que la venda le otorga honestidad, que la balanza pesa los argumentos y que la espada obliga a cumplir la decisión de la dama. Se pretende relacionar estos atributos típicos con el cine, conocido como el séptimo arte, tratando de entender las formas y los modos para representar esta imagen tan popular.

PALABRAS ClAVE: justicia, derecho, cine, arte, séptimo arte.

\section{ABSTRACT}

Law and Art have something in common: their humanistic character. On the other hand, justice, as an ideal, has been represented from the most varied cultural and artistic conceptions. The Western tradition, for example, offers us the image of a woman who uses a bandage on her face, armed in one hand with the scale of saucers and in the other with a sword, elements which allow us to play with that iconography. Then we endow it with a meaning: we assume that the bandage gives it honesty, that the scale weighs the arguments and that the sword forces to fulfill the woman's decision. It intends to relate these typical attributes to the cinema, known as the seventh art, trying to understand the forms and ways to represent this popular image.

KeYwords: Justice, Law, Cinema, Art, Seventh Art.

\section{EL DERECHO Y EL CINE}

Kant sostuvo que la representación de ideas estéticas, es decir, la función del arte, 1 guarda relación con ofrecer más de lo que lingüísticamente puede ser concebido. ${ }^{1}$ Esto porque en el campo perceptivo existe libertad en nuestra conciencia con

1. Immanuel Kant, Kritik der Urteilskraft, citado por Niklas Luhmann, El arte de la sociedad (México D. F.: Herder, 2005), 235. 
respecto a encarar una aventura cuando estamos frente a una obra de arte, a diferencia de lo que sucede en el campo lingüístico, en que el proceso puede ser limitado. ${ }^{2}$

En la modernidad, el derecho ha erigido su legitimidad autocalificándose como disciplina científica. ${ }^{3} \mathrm{Y}$ para ello ha trabajado buscando métodos que le doten de racionalidad. Sin embargo, en esa ardua y cansada búsqueda ha perdido espacio el ser humano, tal y como es. Nos olvidamos que la vida social es un todo, mientras el derecho una lente por medio de la cual se la concibe. ${ }^{4}$

Frente a esa necesaria rigurosidad, exhaustividad o sistematicidad que el derecho encarna, surge la necesidad de, sino regresar al origen, nutrirnos de él, para crear una visión general, inclusiva e interdisciplinaria. Hoy mismo se discute la posibilidad de enlazar las ciencias sociales con las jurídicas, siendo que las dos atienden al mismo sujeto de estudio. Salas sostiene que la comunicación entre ciencias es posible solo después que el ser humano quiera que el elemento volitivo trabaje en ello. ${ }^{5}$

En un mundo complejo, las relaciones entre las ciencias y su abordaje integral resultan casi vitales. Se ha activado un proceso en el cual el derecho busca restablecer relaciones con las realidades circundantes, con los fenómenos sociales. ${ }^{6}$ Para ello se entrecruzará con la filosofía, la sociología, la política y la historia, solo por mencionar algunas. Qué mejor forma de hacerlo si para ello recurre a la séptima de las bellas artes, como una mirada estética que nos permite observar al ser humano y sus circunstancias. Por esa razón, no sorprende que en la actualidad se busque enseñar derecho por intermedio de las artes, aunque sea de forma incipiente. ${ }^{7}$

Con razón, Rivaya y De Cima sostienen que la fusión entre derecho y cine debe ser analizada más allá de una actividad lúdica y formativa, debe permitir además quebrar esa realidad compartimentada que tenemos del mundo y sus fenómenos. ${ }^{8} \mathrm{El}$ cine, como representación estética, nos invita a auscultar realidades y sobre la base de aquello cuestionarnos, indagarnos y reinventarnos como seres humanos.

2. Luhmann, ibíd., 235.

3. Roger Berkowitz, Democratic Legitimacy and the Scientific Foundation of Modern Law, citado por Valentín Thury Cornejo, “El cine, ¿nos aporta algo diferente para la enseñanza del Derecho?”, Academia. Revista sobre enseñanza del Derecho, año 7, n. 14 (2009): 61.

4. Benjamín Rivaya y Pablo De Cima, Derecho y cine en 100 películas: una guía básica (Valencia: Tirant lo Blanch, 2004), 17.

5. Minor E. Salas, "Interdisciplinariedad de las ciencias sociales y juridicas: ¿Impostura intelectual o aspiración científica?", Revista de ciencias sociales, n. ${ }^{\circ}$ 113-114 (2006): 68.

6. Cornejo, “El cine, ¿nos aporta algo diferente para la enseñanza del Derecho?”, 62-3.

7. La universidad ecuatoriana ha tomado nota de esta buena práctica. Bajo módulos como "Dimensiones culturales del derecho y la justicia", "Miradas estéticas del derecho y la justicia" o simplemente como "Cine y Derecho", pretende innovar en el espacio académico.

8. Rivaya y De Cima, Derecho y cine en 100 películas, 97. 


\section{LA DAMA DE LA JUSTICIA}

La justicia puede ser advertida como un concepto superior en el desarrollo de la sociedad -ya sea que su origen pase por la diosa $\mathrm{Ma}$ 'at, quien en el antiguo Egipto era representada por la luz del sol como fuente de verdad y justicia, ${ }^{9}$ o por la griega Dice o la romana Iustitia, representantes del orden justo-, lo cierto es que se ha mantenido presente en el imaginario colectivo como un ideal o deber ser.

Sorprendente resulta el hecho de que desde la Edad Media haya tomado una forma o figura tan reconocida al punto de ser la más popular de entre las virtudes cardinales y teologales, ${ }^{10}$ cuyas figuras hoy nos resulta difícil identificar. De esta manera, la imagen femenina con los ojos vendados, sosteniendo en sus manos una espada y una balanza, ha sido la representación iconográfica que la arquitectura judicial del siglo XIX grabó en las mentes de la sociedad como el símbolo de ese derecho a impartir justicia. ${ }^{11}$

Esta justicia que, por supuesto, obedece a una construcción social de occidente, constituye una representación artística que nos permite jugar constantemente con sus elementos y además otorgarles conceptos para elaborar infinidad de metáforas y alegorías. Y a pesar de que la justicia fue conceptualizada primariamente desde otras bellas artes como la pintura, arquitectura y escultura, conviene observarla desde un arte más vanguardista como supone aquella que se encarga de reproducir imágenes simultáneas.

El séptimo arte, desde sus orígenes, ha mantenido una estrecha relación con el derecho. Así se pueden encontrar un sinfín de películas cuya trama central gira alrededor de un conflicto y la decisión que tomen los jueces. ${ }^{12}$ Pero analizar los elementos que componen esa imagen de la justicia en películas donde el eje central es precisamente el desarrollo de un proceso, puede resultar redundante. Por esa razón se propone, en el presente ensayo, mostrar la venda, la balanza, la espada y la dama también en obras cinematográficas ajenas al thriller judicial. No por eso pierden efectividad o vigencia, ya que ayudan a representar igualmente esa concepción intrínseca de justicia que se forma en nuestro ser por medio de la cultura.

Cabe recalcar que el presente trabajo no constituye un resumen de las cintas a exponerse, no se acerca a tratar toda la problemática que gira en torno a la trama de

9. José María González García, La mirada de la justicia: ceguera, venda en los ojos, velo de ignorancia, visión y clarividencia en la estética del derecho (Madrid: Antonio Machado Libros, 2016), 32.

10. Dennis Curtis y Judith Resnik, Images of Justice, citado por Ignacio Tedesco, El acusado en el ritual judicial: ficción e imagen cultural (Buenos Aires: Editores del Puerto, 2007), 241.

11. Tedesco, El acusado en el ritual judicial..., 238.

12. Ernesto Albán Gómez, Derecho, sociedad y cultura (Quito: Ediciones Legales, 2011), 61. 
las mismas, ni siquiera a los dramas complejos de todos sus personajes. En cambio, el análisis ofrece tomar determinadas escenas para justificar los puntos de vista del autor con respecto al tema propuesto. Por lo tanto, es casi mandatorio observar las películas para entender íntegramente las consideraciones aquí expuestas.

\section{CUATRO PELÍCULAS A PROPÓSITO DE LA DAMA}

Con once nominaciones a los premios Óscar y seis a los Globos de Oro, la obra dirigida por Stanley Kramer, Judgment at Nuremberg ${ }^{13}$ representa un icono en la historia del cine mundial y, por supuesto, en el subgénero judicial. Precisamente, uno de los logros que se le atribuye a esta pieza artística no solo es la prolijidad de sus actores y actrices, sino la habilidad del guion para crear una ficción, tras hechos reales ocurridos después de la Segunda Guerra Mundial, específicamente enfocados en los juicios de Núremberg. ${ }^{14}$

El hilo argumental transcurre en 1948, aproximadamente a tres años de terminada la guerra. Los procesos jurisdiccionales abiertos en contra de los funcionarios capturados del régimen nacionalsocialista se están llevando a cabo. En ese sentido, se instala un juicio contra un grupo de juristas que plegaron a esta ideología y a quienes se les acusa de justificar y legitimar crímenes en contra de la humanidad, sobre todo en lo atinente a políticas de esterilización, amparados en la idea de eliminar seres débiles en una sociedad en la que debía prevalecer una raza superior.

Dan Haywood, un juez norteamericano, llega a Núremberg para presidir estos juicios. Apenas comienza la película, este personaje reconoce su labor y está consciente de la misma, al punto de saberse un juez común, en el sentido de que acepta el encargo para juzgar, aun cuando sabe que él fue seleccionado por descarte de tantos otros que no quisieron asumir ese reto, pues en el imaginario colectivo no existía acuerdo para juzgar a estas personas. Un pequeño guiño de la cinta ocurre en este punto, ya que el juez Haywood está convencido desde el principio de que médicos, empresarios, juristas y demás deben ser llamados a rendir cuentas por los crímenes cometidos durante los años de la Alemania nazi.

13. Stanley Kramer, Judgment at Nuremberg, DVD (Estados Unidos: Roxlom Films, 1961).

14. Los juicios de Núremberg son una serie de procesos judiciales, entablados por los vencedores de la Segunda Guerra Mundial, en contra de dirigentes, médicos, juristas, y en general funcionarios que sustentaron y justificaron con su accionar la ideología nacionalsocialista de Hitler. La razón de existencia de estos juicios todavía causa polémica debido a que en su mayoría fueron juzgados vulnerando principios como el de imparcialidad y legalidad, por mencionar solo dos de ellos. 
Uno de los procesados, el juez Ernst Janning, es presentado como íntegro, humano, intelectual y justo, al punto que resulta casi un agravio juzgarlo. Esa disyuntiva invade al juez Haywood, quién para estar seguro de juzgarlo, a más de las pruebas que se ventilan por parte de la acusación, se ve obligado a tomar en consideración otros elementos extrajudiciales. Por ejemplo, analiza el párrafo de un libro escrito por este y titulado El sentido de la ley, donde visualiza una Alemania nueva sin armas y sin derramamiento de sangre, un país consciente, libre, humano.

En otra escena, Mrs. Bertholt, viuda de un militar nazi ejecutado, se vuelve confidente del juez Haywood, y una noche durante una conversación, ella le habla de Ernst Janning, reconociéndolo como un ser noble que incluso aborrecía a Hitler. En otra escena, ella le dice que es necesario olvidar para seguir viviendo, que no es preciso vivir odiando. Finalmente, el propio procesado, pese a los esfuerzos de su defensa por demostrar que solamente respeta la ley establecida, pide la palabra y se declara culpable de condenar a personas a morir en campos de concentración, con el convencimiento que lo hacía para proteger a su patria. La deliberación es leída y los procesados declarados culpables a reclusión perpetua.

Para efectos de este ensayo, la figura del juez Haywood encarna la famosa venda, ${ }^{15}$ como "símbolo positivo de la imparcialidad de la justicia" ${ }^{16}$ Esto porque recibió presiones de parte del pueblo alemán, por intermedio de la opinión pública, e incluso del propio Estado norteamericano, por medio de sus autoridades. Particularmente, la presión infligida ya por Mrs. Bertholt, con su discurso alusivo al olvido y a la compasión, ya por los militares y senador de los Estados Unidos, quienes también recomiendan al juez un fallo benévolo, e incluso por los argumentos de uno de los miembros del tribunal, quien finalmente termina ofreciendo un voto disidente, lo cierto es que Dan Haywood termina aplicando rigurosas penas.

La metáfora de la venda en la justicia muestra la necesidad de una persona imparcial, un ser neutral que no diferencie ni privilegie intereses particulares, sean estos de orden económico, social o ideológico. La decisión del juez se mantiene incólume hasta el final cuando Ernst Janning, aceptando el fallo como justo, pretende excusarse sosteniendo que no pensó que su actuar desembocaría en el asesinato de millones de personas, a lo que Haywood le replica sosteniendo que se llegó a eso desde el primer momento en que Janning condenó a un inocente.

15. Hay que recalcar que la venda en el rostro de la justicia aparece como un símbolo negativo por primera vez desde el grabado publicado en 1494 por Sébastien Brant, y la idea era ridiculizar a la dama, dándole tintes de locura y necedad. Luego se transforma en símbolo de honestidad, integridad y honradez. González García, La mirada de la justicia..., 128-9.

16. Ibíd., 128. 
En este punto, conviene hacer un paréntesis y ajustar una noción de justicia. En atención al contexto, me referiré a la dogmática penal en general y a la pena en particular. Esto como fundamento del derecho de castigar que tiene el Estado. Se parte de la idea primaria de que a la comisión de un delito le sigue, por asunto de justicia, una pena. De esta forma, la pena tiene dos significados, a saber: retributivo (absoluta) y preventivo (relativa) ${ }^{17}$ Desde la teoría de la pena, la primera categoría sostiene que la pena es una respuesta justa al delito provocado por el autor, mientras la segunda sustenta que la pena, justa también, previene la comisión anterior o posterior del ilícito penal. ${ }^{18}$

Con respecto a la cinta expuesta, está claro que, de forma directa, las penas impuestas obedecen principalmente a la prevención general positiva, entendida como ese valor simbólico que refuerza la confianza en el derecho como sistema. ${ }^{19}$ Es decir, tras el juzgamiento a los altos mandos alemanes se quiso transmitir la idea a la sociedad y a los Estados de que en adelante deberán observar irrestrictamente los derechos humanos, con el fin de que esos crímenes, a pesar de no estar tipificados aún, no se vuelvan a perpetrar.

Siguiendo con los dos símbolos que acompañan a la justicia, uno en cada mano, es menester mencionar que no le pertenecen exclusivamente a ella. Por citar solo unos ejemplos: el arcángel San Miguel también ostenta una espada y balanza, elementos que comparte con la figura del monarca en el Leviatán de Hobbes, ${ }^{20}$ y no hay que dejar de lado la imagen de Cristo y las escrituras, donde recurrentemente son mencionados.

The Dark Knight ${ }^{21}$ tuvo ocho nominaciones a los premios Óscar, una a los premios Goya, entre otros. Cronológicamente, la historia es la segunda perteneciente a la trilogía de Batman entregada a Christopher Nolan para su dirección. Cinta que pasará a la historia por la actuación sobresaliente del personaje de reparto Heath Ledger encarnando al Joker, en su última actuación antes de su desaparición.

17. Rosario de Vicente Martínez, El color de la justicia. Tres colores: rojo (Valencia: Tirant lo Blanch, 2003 ), 51.

18. Ángela María Buitrago Ruiz, "Fundamento y fin de la pena: consecuencias jurídicas y justicia restaurativa”, en Derecho penal y sistema acusatorio en Iberoamérica, ed. por Antonio José Cancino Moreno (Bogotá: Universidad Externado de Colombia, 2003), 365-6.

19. Eugenio Raúl Zaffaroni, Alejandro Alagia y Alejandro Slokar, Manual de Derecho Penal: parte general (Buenos Aires: Ediar, 2006), 42. Hay que aclarar que el profesor argentino, independientemente de la conceptualización de las teorías positivas de la pena, no cree en ellas y las cataloga como falsas con el argumento de que la pena no es un bien para nadie, ni para el sujeto que delinque, ni para la sociedad, pues lo único que refuerza es la irracionalidad de la sociedad moderna.

20. González García, La mirada de la justicia..., 18.

21. Christopher Nolan, The Dark Knight, DVD (Reino Unido y Estados Unidos: Warner Bros. Pictures, 2008). 
El espectador presencia una ciudad Gótica al borde del caos. El tráfico de drogas, la delincuencia común y, lo más preocupante, el crimen organizado se han tomado las calles. Para agravar la situación, Batman es perseguido por los daños colaterales que resultan de sus intervenciones nada convencionales. El desarrollo de la cinta presenta una lucha encarnizada entre el héroe y su némesis The Joker, con la particularidad de que los dos se mueven en las sombras, lo que vuelve más interesante la trama. Sin embargo, alguien tiene que dar la cara ante la metrópoli, y ese es justamente Harvey Dent, el fiscal de la ciudad.

Para efectos del ensayo, la decisión de Batman representa esa efigie que simula una balanza. Para nadie es un secreto que el accionar de los superhéroes está al límite del orden establecido por las licencias que se permiten al momento de combatir el crimen. Batman sabe de esa pugna y está consciente de que frente al hampa necesita una figura popular, de carne y hueso, pero sobre todo que le otorgue legitimidad al sistema ordinario, al sistema legal. Frente al caballero de la noche, como ha sido calificado Batman, se requiere un caballero blanco.

El platillo de la balanza está representado, de un lado, por la delincuencia organizada, quienes entregan el poder al Joker, mientras del otro se encuentra Harvey Dent, con el acuerdo de Batman, quien, en sentido estricto, cede su lugar a un personaje revestido de legalidad debido al cargo que desempeña. De esta manera, el argumento que da inicio al largometraje gira alrededor de un grupo de mafiosos que pretenden camuflar en los bancos el dinero de sus negocios, para lo cual cuentan con un empresario oriental, quien ante la amenaza se encarga de trasladar esos fondos, huyendo de ciudad Gótica y justamente evitando la jurisdicción del fiscal, no así la de Batman. Razón por la que hasta el desenlace fílmico, este último representará la ilegalidad, nótese cuando secuestra clandestina e ilegalmente a este empresario chino, mientras Dent, a pesar de los hechos, muere como héroe, nuevamente con la anuencia del superhéroe.

Especulando, el caballero de la noche pudo combatir al Joker directamente, pero se sabe ilegal e ilegítimo debido justamente a las voces discrepantes que ponen en duda la actuación de un personaje enmascarado que contraviene los más elementales principios de la democracia. En su lugar, para sopesar la mafia, nivela la balanza dándole a ciudad Gótica un ser visible, necesario para que los ciudadanos crean en las instituciones, en la justicia. La balanza, como símbolo de igualdad, ratifica la paridad entre pesos sobre un punto concreto, y garantiza el equilibrio. ${ }^{22}$

22. Christian-Nils Robert, Une allégorie parfaite: La Justice. Vertu, courtisane et bourreau, citado por Tedesco, El acusado en el ritual judicial..., 239. 
De acuerdo con la noción de justicia ensayada, con las teorías de la pena, la decisión del caballero de la noche vuelve a estar ligada, ahora indirectamente, con esta representación de la prevención general positiva, porque la motivación del personaje principal es mantener la fidelidad al derecho, las instituciones y las autoridades.

La siguiente cinta La Ley de Herodes, ${ }^{23}$ es una comedia mexicana de Luis Estrada, nominada a los premios Ariel, La Habana y Sundance. Este largometraje entrega quizá el elemento simbólico de la justicia más palpable de todos los aquí expuestos. La sátira política que mezcla la brillante actuación de Damián Alcázar acompañado de personajes turbios pero fascinantes, con una banda sonora sobresaliente y una historia nada ajena sobre una forma particular de hacer política, otorgan a esta obra un aire de redención. Lo atractivo de esta muestra cinematográfica es la inseguridad para rotularla en el campo del realismo mágico, donde el adjetivo "mágico" puede desaparecer y eventualmente pasar desapercibido.

La sátira toma lugar en 1949, en un pueblo ficticio llamado San Pedro de los Saguaros, localidad que a primera vista goza de fama de ser ingobernable. La llegada de un presidente municipal interino, representado por el licenciado Juan Vargas, supone un reto de orden personal. La impresión de este personaje y su cónyuge al llegar al pueblo es decepcionante. De ahí en adelante, el conflicto existencial de Vargas será el motor de este cuento, cuando se cuestione sobre los medios para cumplir el mandato de "modernidad y justicia social" promovido por su presidente y su partido, el PRI.

Desesperado e ignorante ante el panorama miserable que le ofrece el pueblo, cuyos escasos habitantes son analfabetos, con un burdel foco de riñas y asesinatos, donde el párroco perdona pecados cobrando dinero y un enemigo político respirándole en la espalda, Vargas apenas puede sobrevivir, cuestionándose cómo obtener recursos para hacer efectivas las promesas de campaña. En este punto tiene convicciones de hacer política de una manera honesta, pero se da cuenta de que aquella actitud, en lugar de solucionar los problemas, los ahonda. Con el presupuesto en cero y ante el olvido del gobierno central, decide viajar a la ciudad y reclamar una asignación presupuestaria para ejercer sus actividades.

La respuesta de su secretario de Gobierno es sencilla y mordaz al mismo tiempo. Le entrega un compendio de leyes federales y estatales, en el que existen impuestos, faltas al orden público, contravenciones e incluso delitos, correspondiéndole a cada una de ellas el cobro de multas. Vargas tiene dudas sobre la aplicación de las leyes que le acaban de entregar, básicamente porque no tiene forma de hacerlas cumplir, ya que

23. Luis Estrada, La Ley de Herodes, DVD (México: Bandidos Films, 1999). 
no tiene fuerza pública que lo respalde. Esa autoridad, de la que no se siente seguro Vargas, se la ejerce, según el secretario, con un revólver.

La representación de la justicia lleva la balanza en una mano y la espada en la otra, de manera que la espada sin balanza es el poder desnudo, mientras la balanza sin la espada la impotencia del derecho; así, mientras la balanza pesa, la espada ejecuta. ${ }^{24}$ Obviamente, las frases de Jhering atienden al contexto de un Estado de derecho distinto al que propone el director en esta película; sin embargo la metáfora sirve para representar el significado de la espada para la justicia, así como el revólver para Vargas. En adelante se paseará por el pueblo cargando de un brazo el compendio de leyes y del otro el arma para hacerlas respetar.

Está claro que el revólver conlleva un lenguaje negativo en el largometraje, pero el ejercicio propuesto es claro en cuanto a la conceptualización. La justicia, desde la concepción divina inclusive, ${ }^{25}$ requiere de la fuerza, la coacción, el poder de sometimiento para el caso en que los ciudadanos no quieran ceder ante la misma. El desenlace, siempre en tono sarcástico, confirma esa justicia necesitada de la fuerza.

Posiblemente este elemento justifique no solo la existencia de la teoría de la pena sino incluso la existencia del propio poder punitivo estatal, entendido como ese derecho que el soberano, el rey, la república le usurpó a la víctima ${ }^{26}$ con la justificación de que el delito rebasa el daño particular y afectando a la colectividad. ${ }^{27}$ Esa fuerza representada en la espada de la justicia es la pena, el castigo, la existencia y razón del poder punitivo en la forma en que ha sido concebido históricamente.

Finalmente, la feminidad cierra la metáfora. Si hay una representación de esa justicia encarnada por una mujer hay que observar la reciente cinta de Martin McDonagh. Nominada a seis premios Óscar, seis Globos de Oro y ocho Bafta, este relato cinematográfico lleva el poder de su protagonista al máximo. Three billboards outside Ebbing, Missouri, ${ }^{28}$ cuyo título en español, Tres anuncios por un crimen, nos acerca más al contenido real del film, relata la historia de Mildred Hayes, una obstinada mujer con hambre de justicia.

24. Rudolf von Jhering, Der Kampf um Rechts, citado por González, La mirada de la justicia..., 19.

25. En la Biblia se hacen constantes referencias a la justicia representada generalmente con símbolos como la espada para invocar fuerza. Referencias como "la espada afilada del Señor" (Ez. 21) o "la espada encendida" (Gn. 3:24) son solo dos ejemplos.

26. Zaffaroni, Alagia y Slokar, Manual de Derecho Penal, 7.

27. Mariana Trebisacce, "Mediación: ¿alternativa al Derecho Penal o a la pena?", en Mediación penal: reparación como tercera vía en el sistema penal juvenil, ed. por Zulita Fellini Gandulfo (Buenos Aires: Depalma, 2002), 64.

28. Martin McDonagh, Three billboards outside Ebbing, Missouri (Estados Unidos y Reino Unido: Film4 Productions, 2017). 
Desesperada por la violación y muerte de su hija, decide alquilar tres vallas publicitarias enormes, donde interpela resultados al jefe de policía del lugar Bill Willoughby, ya que han pasado algunos meses sin que existan indicios sobre los responsables de semejante atrocidad. Sin embargo, este accionar despierta rechazo en la población, toda vez que coinciden en que Willoughby es un buen oficial, quién además despierta compasión colectiva, pues ha sido diagnosticado con cáncer. La propia Hayes sabe del drama que vive el jefe de policía, a pesar de lo cual no está dispuesta a quitar esos carteles.

La fortaleza de esta mujer la lleva a enfrentarse al párroco de la localidad, a su expareja, a su propio hijo, tomando incluso acciones efectivas y radicales como incendiar la estación de policía y agredir físicamente a sus vecinos. El drama se ahonda cuando el jefe de policía se suicida y entonces el pueblo entero se vuelca en su contra. Lo cierto es que el temple de la mujer no cede ante las presiones que se le cruzan en todas direcciones.

Hayes representa a esa justicia como mujer, firme, determinante, incorruptible. Si bien nunca logró descubrir al asesino de su hija, jamás desmayó en su cometido. Sobre el final ella viaja junto con el policía Dixon a Idaho, aparentemente decididos a liquidar a un presunto violador, sin que sea precisamente el que atacó a su hija, pero en el camino van a pensar dos veces sobre esta decisión.

Este desenlace incierto nos abre la puerta a la anacrónica teoría absoluta de la pena, que, como se ha dicho, la justifica porque este mal no debe quedar exento de castigo, siendo que el responsable debe recibir su merecido. ${ }^{29}$ La posible reacción de Hayes y Dixon dibuja acaso la conocida ley del Talión, olvidada ya en la dogmática penal, pero muy presente en el imaginario social.

Zaffaroni y Trebisacce coinciden en que las teorías que fundamentan la pena, cualquiera sea su clasificación, han fallado, no solo porque son falsas según el primero de ellos, sino porque, para ella, ninguna ha logrado alcanzar su finalidad teórica. La cárcel, desde la venganza pura, multiplica el sufrimiento rebasando con creces el daño inicial, mientras desde la prevención, ni disuade ni socializa a nadie en la forma en que es aplicada. ${ }^{30}$

En contraposición, siempre estará pendiente pensar una justicia distinta, una que se encargue de restaurar. Por lo pronto, el cine nos enseña que la dama de la justicia con venda, balanza y espada nos sigue cautivando con esa figura impoluta. Quizá invitándonos a repensar sobre sus elementos simbólicos, a quitarle unos y ponerle otros.

29. Vicente Martínez, El color de la justicia..., 51.

30. Zaffaroni, Alagia y Slokar, Manual de Derecho Penal, 63. 


\section{CONCLUSIONES}

Las líneas aquí ensayadas han sido posibles debido a la universalidad del lenguaje que solo las artes saben lograr. Ayuda que guionistas, escritores y directores estén conscientes de que el centro de una problemática cinematográfica sea el conflicto humano. Y solo luego de que existe un problema social conviene analizarlo desde una lógica que permita resolver o ahondar ese conflicto. Ahí entra el derecho, la ley o cualquiera de sus acepciones, en sentido estricto.

Pero el cine es más. Permite al espectador ser parte de una historia, al tiempo que destruye límites franqueados por el conocimiento formal. Por medio de las imágenes muestra una realidad alternativa en la que el espectador recibe muchos datos en pocos minutos, lo que lo vuelve masivo. En el campo didáctico ayuda a entender conceptos complejos, sea que provengan del derecho mismo o de cualquiera de las disciplinas sociales, permitiendo muchas veces el juego entre ellas.

En tanto humano, el cine nos introduce en mundos fascinantes. Nos permite observar el dolor, la alegría, la nostalgia, el amor, el odio, pero sobre todo nos permite vivirlo. Esto porque por medio del relato secuencial, el espectador se vuelve un personaje más dentro de la trama, cuyo medio es transportar, pero cuyo fin es deleitarnos con un pedazo de historia. Las películas nos permiten experimentar tantas emociones como cuentos posibles, situación que ha llevado al cine a ocupar la casilla de la séptima de las bellas artes.

Luego hay que diferenciar que, independientemente del argumento, la historia narrada siempre va a ser supuesta. Es decir, esa ficción subsiste un momento, durante el cual nos somete. Tiempo en el cual generamos empatía o antipatía con personajes o situaciones diversas. Por eso hasta cierto punto, y dependiendo de la película, mientras nos permite ser parte de la misma, nos obliga a buscar tantas alternativas y explicaciones como problemas aparezcan. Nos lleva a indagar, proponer, elucubrar.

Eso acontece con las películas analizadas, las que, salvo una, tratan de diversos temas sin que sean necesariamente jueces y abogados sus protagonistas. Se han expuesto cintas que contienen un trasfondo sociológico, filosófico, pasa por lo histórico y termina en lo político. Lo cierto es que todas nos dejan elementos para analizar y repensar la justicia. En esta ocasión, la mirada estética del cine nos sirve para escudriñar acerca de esta dama a quienes todos hemos visto alguna vez en las facultades de Derecho, juzgados o tribunales, e incluso en forma de cuadros o adornos en los despachos de los abogados.

En forma general, la imagen escogida en este ensayo ha sido, sin lugar a dudas, la representación de una justicia en el imaginario occidental, y los elementos que la acompañan en la personificación son minuciosamente conceptualizados y discutidos 
sin que exista una posición determinada. Solo así se puede explicar el hecho, por ejemplo, de la venda en el rostro como virtud y defecto. Si la tiene muestra ecuanimidad, pero también ceguera. Esta argumentación para decir que, en el presente trabajo, la interpretación dada a los elementos que la representan apenas constituye una de tantas posibles, sin que el discurso se encuentre terminado.

Lo mencionado es útil para sostener, en forma particular, que la visión otorgada por el autor es más personal aún. Significa que los creadores de las obras expuestas no necesariamente pensaron en una balanza o en una espada en el momento de su inspiración. En cambio, cuando hacen cine y exponen una problemática social, en tanto humanos, buscan que la cinta conecte con el público, pensando ahora sí en un sentimiento universal como la justicia.

Sin embargo, en el desarrollo de este trabajo se advirtió una consecuencia no calculada. Al tomar la imagen de esta dama y relacionarla con la teoría de la pena, se llega a la conclusión de que esta figura sustenta y legitima la existencia del castigo, que en el campo penal se muestra en forma agresiva. Es una efigie que se lleva bien con la pena como retribución y/o prevención, pero no con una pena como restauración. Lo complejo es entender que esas historias, en su desenlace, puedan parecernos más reales de lo que imaginamos.

En fin, que a la justicia unos la ridiculicen como en La Ley de Herodes, que otros la vanaglorien como Judgment at Nuremberg, que la relativicen como en The Dark Knight, o finalmente la critiquen como en Three billboards outside Ebbing, Missouri, lo cierto es que algo le dicen al espectador, más al empecinado en encontrar justificación para esa iconografía que la simboliza. Bien otorgado el título del séptimo arte, porque el cine no solo instituye una reproducción de planos secuenciales con actuaciones, bandas sonoras, fotografías, vestuarios, sino sobre todo porque con ello toca fibras en el público motivándolo a que cuestione, indague, reinvente.

\section{BIBLIOGRAFÍA}

Albán Gómez, Ernesto. Derecho, sociedad y cultura. Quito: Ediciones Legales, 2011.

Buitrago Ruiz, Ángela María. "Fundamento y fin de la pena: consecuencias jurídicas y justicia restaurativa". En Derecho Penal y sistema acusatorio en Iberoamérica, editado por Antonio José Cancino Moren, 363-81. Bogotá: Universidad Externado de Colombia, 2003.

Estrada, Luis. La Ley de Herodes. DVD. México: Bandidos Films, 1999.

González García, José María. La mirada de la justicia: ceguera, venda en los ojos, velo de ignorancia, visión y clarividencia en la estética del derecho. Madrid: Antonio Machado Libros, 2016.

Kramer, Stanley. Judgment at Nuremberg. DVD. Estados Unidos: Roxlom Films, 1961. 
Luhmann, Niklas. El arte de la sociedad. México D. F.: Herder, 2005.

McDonagh, Martin. Three billboards outside Ebbing, Missouri. Estados Unidos y Reino Unido: Film4 Productions, 2017.

Nolan, Christopher. The Dark Knight. DVD. Reino Unido y Estados Unidos: Warner Bros. Pictures, 2008.

Rivaya, Benjamín, y Pablo De Cima. Derecho y cine en 100 películas: una guía básica. Valencia: Tirant lo Blanch, 2004.

Salas, Minor E. "Interdisciplinariedad de las ciencias sociales y jurídicas: ¿impostura intelectual o aspiración científica?". Revista de Ciencias Sociales, n. ${ }^{\circ}$ 113-114 (2006): 55-69.

Tedesco, Ignacio. El acusado en el ritual judicial: ficción e imagen cultural. Buenos Aires: Editores del Puerto, 2007.

Thury Cornejo, Valentín. “El cine, ¿nos aporta algo diferente para la enseñanza del Derecho?”. Academia. Revista sobre enseñanza del Derecho, año 7, n. ${ }^{\circ} 14$ (2009): 59-81.

Trebisacce, Mariana. “Mediación: ¿alternativa al Derecho Penal o a la pena?”. En Mediación penal: reparación como tercera vía en el sistema penal juvenil, editado por Zulita Fellini Gandulfo, 61-70. Buenos Aires: Depalma, 2002.

Vicente Martínez, Rosario de. El color de la justicia. Tres colores: rojo. Valencia: Tirant lo Blanch, 2003.

Zaffaroni, Eugenio Raúl, Alejandro Alagia y Alejandro Slokar. Manual de Derecho Penal: parte general. Buenos Aires: Ediar, 2006. 